\title{
Del APRA a FORJA y de FORJA al peronismo Reflexiones sobre las redes del aprismo en Argentina a través del itinerario político e intelectual de Francisco Capelli
}

\author{
Leandro Sessa \\ Universidad Nacional de La Plata, Argentina. \\ lesessa@yahoo.com.ar
}

\begin{abstract}
RESUMEN
La perspectiva transnacional ha renovado en los últimos años la historiografía sobre la Alianza Popular Revolucionaria Americana (APRA), a partir de problemas y abordajes que no recorren los temas de las disputas entre sus defensores y detractores en Perú. Dicha renovación ha permitido restituir la dinámica de las redes del aprismo en el continente. Este trabajo procura aportar algunos hilos más al conocimiento de esas redes, a través del itinerario político e intelectual de Francisco Capelli. Se trata del caso de un militante que impulsó la formación de un sindicato aprista de estudiantes en la ciudad de La Plata, Argentina, en la década del treinta, y luego se desempeñó como dirigente de la organización Fuerza de Orientación Radical de la Joven Argentina (FORJA), en donde llegó a ocupar el cargo de Secretario General. Esta organización nacionalista, desprendida del tronco de la Unión Cívica Radical (UCR), se incorporó más tarde al peronismo, y Capelli formó parte de la gestión del gobierno de la Provincia de Buenos Aires. La elección de este caso en particular exige una serie de aclaraciones introductorias, que resultan una excusa para reflexionar, también, acerca del lugar del relato biográfico en la historiografía sobre el APRA.
\end{abstract}

Palabras clave: Política, aprismo, historiografía.

\section{From APRA to FORJA and FORJA to Peronism. Reflections on the aprismo networks in Argentina through the political and intellectual itinerary of Francisco Capelli}

\begin{abstract}
The transnational perspective has renewed in recent years the historiography on APRA, from problems and approaches that do not cover the issues of disputes between its defenders and detractors in Peru. This renewal has allowed to restore the dynamics of aprismo networks in the continent. This work seeks to contribute some more threads to the knowledge of these networks, through the political and intellectual itinerary of Francisco Capelli. This is the case of a militant who promoted the formation of an APRA union of students in the city of La Plata, Argentina, in the thirties, and then served as leader of the organization Fuerza de Orientación Radical de la Joven Argentina ( FORJA), where he became the Secretary General. This nationalist organization, detached from the trunk of the Radical Civic Union (UCR), was later incorporated into Peronism, and Capelli was part of the management of the government of the Province of Buenos Aires. The choice of this particular case requires a series of introductory clarifications, which are an excuse to reflect, also, on the place of the biographical account in the historiography on APRA.
\end{abstract}

KeYwords: Politics, aprismo, historiography. 


\section{Apuntes para una reflexión sobre la biografía en la historiografía sobre el APRA}

La decisión de centrar el estudio en un caso individual supone definir un posicionamiento respecto del uso de la biografía en la reconstrucción histórica. Si bien existen diccionarios biográficos, que han nutrido el conocimiento de actores fundamentales de la historia político-intelectual, el relato centrado en una experiencia de vida ha alcanzado cierto lugar de reconocimiento académico, asumiendo los desafíos que supone introducir una perspectiva que parecía un patrimonio de la literatura de divulgación, sin una suficiente problematización. Tal como advierte Paula Bruno, en las últimas décadas la discusión sobre las biografías ha dado lugar a un corpus de reflexiones que, además de «habilitar» su utilización para el análisis histórico, han definido distintos ejes de debate.

Sin adentrarnos en profundidad en la cuestión, resulta interesante reponer la tensión señalada por Bruno (2016) entre la posibilidad de utilizar el enfoque biográfico como un género, un método o un recurso.

Más allá de la posibilidad de superponer estos elementos, cada uno de estos «usos» supone decisiones respecto de la inscripción de la biografía en el análisis histórico. En este sentido, advertimos que aquí no pensamos el enfoque como un género, ni buscamos definir una epistemología específica, capaz de revelar nuevos elementos de la Historia. La utilización se acerca más a la idea de definir la biografía como un recurso que ofrece una ventana para pensar los procesos históricos, en este caso las redes continentales del aprismo; pero al mismo tiempo, tomado el caso como ejemplo o como excepción, se propone no reducir la experiencia individual a las determinaciones generales.

La biografía, claro está, no es una novedad en los estudios sobre el APRA. De hecho, es posible señalar que buena parte de las reconstrucciones históricas tuvieron inicialmente un punto de partida centrado en la experiencia individual. La vida y obra de Haya de la Torre resultó tempranamente un tema de interés, hasta el punto de confundirse su biografía con la del APRA. Fue la reconstrucción de sus ideas, militancia, exilios y redes personales, una de las primeras formas de acercarse a la dimensión continental del aprismo, fundamentalmente a partir de los libros escritos por su principal biógrafo: el escritor Luis Alberto Sánchez. Los textos sobre Haya de la Torre escritos por Sánchez, de acuerdo con la caracterización mencionada previamente, responden a la definición de la biografía como un género. La narración contiene numerosos giros literarios, a través de los cuales se construye una historia que, resumida en la vida de Haya, sintetiza la identidad del APRA. Las biografías dibujan un recorrido que va desde las inquietudes y las reflexiones personales, a la conformación de una vocación que se expresa en el terreno de la política. Esa impronta en la narrativa de Sánchez se despliega en textos plagados de anécdotas, que permiten pensar, también, en el público al que estaban destinados. 
Esas producciones biográficas iniciales son indisociables de los objetivos políticos que las enmarcaban. Tantos quienes buscaba construir un relato apologético sobre Haya y el APRA, como quienes se proponían desmitificar o desmontar los relatos consagratorios, recorrían los caminos del texto biográfico, en el que lo anecdótico, el dato de color, o algún acontecimiento omitido, parecía poder llevar al tribunal de la Historia la «verdadera» expresión del principal referente del APRA.

El recurso biográfico era inescindible, entonces, de la construcción de relatos en disputa, en donde las personalidades del aprismo aparecían adornadas de la épica de vidas atravesadas por el compromiso, la persecución, el heroísmo, la coherencia y el martirio, que conformaban elementos centrales en la construcción de la identidad del aprismo; o por el contrario, podían demostrarse las contradicciones entre el discurso autoproclamado y la "verdadera cara» de vidas atravesadas por el temor, el engaño, la manipulación o el pragmatismo, entre otros rasgos negativos.

A esta producción con pretensiones de reconstrucción histórica (alguna muy valiosas, por cierto) habría que sumar una serie de autobiografías que también ocuparon un lugar central entre los escritos sobre el aprismo. Las memorias de los militantes narradas en relatos en primera persona, venían a confirmar o a desmentir el carácter de la experiencia aprista y algunos de los nudos históricos más sobresalientes, a partir de una perspectiva «desde adentro». El testimonio personal aparecía, así, como un recuso de veracidad, irrefutable frente a otros relatos.

Esa centralidad otorgada a las biografías constituyó un rasgo del aprismo alimentado desde sus orígenes por textos y crónicas, que no sólo tenían la pretensión de ofrecerse como reconstrucción histórica, sino que, contemporáneos a la vida política del APRA, poblaban las publicaciones con nombres propios. Los textos que aludían a un individuo en particular, no sólo se centraban en la vida de Haya, sino que permitían también conocer las experiencias de otros dirigentes y militantes, siempre bien adjetivadas con virtudes complementarias con su actividad política, como la oratoria, la creatividad artística, el sacrificio, el heroísmo, etc. Esta difusión de referencias personales no era sólo una forma de propaganda o de presentación ante el público. La pretensión de mostrar coherencia entre las posiciones políticas y la vida personal era un rasgo característico de la militancia en ciertos espacios políticos y fue tempranamente asumida por el aprismo. Eso puede constatarse en la correspondencia, que no tenía pretensiones de ser un documento público y que contiene numerosas referencias a la necesidad de que la vida privada y pública de los militantes estuviera guiada por los mismos valores.

Haya de la Torre a Sánchez (1935). En muchas cartas contrastaba la vida clandestina en Perú con la situación de los exiliados, como una forma de exigirles mayor disciplina. Esas indicaciones tenían referencias a prescripciones sobre la vida personal de los militantes: «A los c.c. dedicados al galanteo ojalá que conciban un hijo con cuatro 
patas [...] Es la gracia que a todos les deseo y que se vayan al infierno con su pereza y su sífilis. Aquí trabajamos. Aquí sufrimos [...] Sólo me preocupa la acción, la batalla, y revitalizar al Partido luchando contra los cobardes y los sensuales. Tarea de hace diez años. Animar, transformar, inocular a estos hombres-falos».

Sánchez, en su correspondencia (1924-1976). La vida nocturna era censurada no sólo porque suponía desviar la atención de los compromisos con el Partido, sino porque se apartaba de cierta moral pública y privada asociada a la identidad del aprismo. Este es un tema interesante para rastrear los modelos de masculinidad construidos o asumidos en torno de la militancia. (Mosca Azul Editores, 1982, p. 49).

En este sentido, la biografía no fue sólo un recurso para la historia del APRA; fue un género atravesado por las lógicas de una historiografía aprista o antiaprista, atrapada dentro de una misma tradición.

Tal vez como una respuesta a esos antecedentes, los estudios que renovaron la historiografía sobre el APRA en las décadas del setenta y ochenta, abandonaron el elemento biográfico en favor de una atención más decidida sobre variables políticas y fundamentalmente económico-sociales. Sin embargo, las autobiografías y los testimonios personales siguieron alimentando las intervenciones sobre APRA; y en muchos casos todavía se enmarcan en las viejas pugnas entre apristas y antiapristas.

Sólo recientemente han aflorado nuevas perspectivas que utilizan elementos biográficos como recursos para un análisis de la experiencia del APRA, interrogada desde dimensiones más complejas.

\section{La biografía de Francisco Capelli o las relaciones del aprismo con el peronismo}

Dentro del panorama reseñado sobre la tradición biográfica en los estudios sobre el aprismo, resulta necesario explicitar cuáles son los aportes que pueden surgir de la reconstrucción de la biografía de Francisco Capelli. Como señalamos en la primera parte del trabajo, Capelli tuvo un breve protagonismo en la construcción de una de las organizaciones apristas en Argentina, y luego participó activamente de FORJA, en donde alcanzó el cargo de Secretario General. Previamente había sido elegido presidente de la Federación Universitaria Argentina (FUA), como representante de la Organización Universitaria Forjista (OUF) y, ante el advenimiento del peronismo, se incorporó a la gestión del gobierno de la Provincia de Buenos Aires en el Ministerio de Hacienda, Economía y Previsión, en donde estuvo a cargo de una subsecretaría vinculada con el área de Turismo Social.

Esta trayectoria permite asomarse a un tema que no ha recibido demasiada atención: las relaciones entre el APRA y el peronismo. Dicha temática constituye un capítu- 
lo relevante de la dimensión continental de la experiencia aprista, y un problema central para el análisis de la historia política y de las ideas en América Latina.

La presencia continental del APRA ha sido objeto de atención principalmente en torno de las redes del movimiento reformista universitario. Esta perspectiva derivó en un interés centrado en la década del veinte. En los años siguientes, sin embargo, Argentina, Chile, México y Guatemala, entre otros países, fueron destinos de militantes del aprismo que debieron exiliarse. Al mismo tiempo existieron iniciativas con el sello aprista impulsadas por militantes que no eran peruanos. Esta trama de la dimensión continental del APRA ha recibido menos atención, y permite explorar las transformaciones, las continuidades y las tensiones de las redes apristas en el continente. En el caso de Argentina, hemos estudiado los vínculos del APRA con el socialismo y la experiencia del Partido Aprista Argentino (PAA), que funcionó con sede en la ciudad de Rosario. Sin embargo, todavía se puede avanzar más en las relaciones entre el aprismo y otros espacios político-ideológicos. Los vínculos con FORJA, por ejemplo, resultan especialmente interesantes debido a que permiten indagar en los contactos establecidos con sectores que abrevaban en un nacionalismo antiimperialista, que buscaba diferenciarse del socialismo, del comunismo y del liberalismo. FORJA había nacido por iniciativa de un grupo de militantes de la Unión Cívica Radical (UCR) que, sin romper con el Partido, cuestionaban la dirección de Alvear y reivindicaban la tradición asociada a las políticas y el liderazgo de Hipólito Yrigoyen. Algunos de sus referentes habían tenido participación en las luchas del movimiento estudiantil en torno del reformismo universitario. Quizás el nombre que más se asocia con esa tradición es el de Gabriel del Mazo, uno de los principales promotores de FORJA.

Más allá de la intervención dentro del radicalismo, FORJA pronto se transformó en un espacio de encuentro de sectores que buscaban definir las bases de un "pensamiento nacional», construido principalmente a partir de la denuncia de la presencia del imperialismo inglés en Argentina. Creció, entonces, como una usina de producción de conocimiento que giraba en torno de denuncias, tanto de los intereses económicos que vinculaban a la oligarquía argentina con empresas de capitales ingleses, como de la estructura legal e ideológica sobre la que se sostenía la trama de un nuevo "coloniaje». Dentro de esas perspectivas, la revisión del relato histórico conformó un nudo programático y generó un acercamiento a lo que ya se conocía con el nombre de «revisionismo histórico». Esta corriente, cuyos referentes eran declarados nacionalistas, cuestionaba las perspectivas sobre el pasado construidas sobre la tradición liberal, a la cual adherían en términos generales las izquierdas. El revisionismo se ocupó principalmente de reivindicar la figura de Juan Manuel de Rosas como representante de una posición nacionalista y popular, que había sido estigmatizada por sus detractores liberales.

En 1940, FORJA permitió el ingreso a la organización de militantes no afiliados a la UCR, lo cual profundizó el distanciamiento con el radicalismo. Frente al ascenso de 
la figura de Perón y la emergencia del fenómeno peronista, en 1945, la agrupación se disolvió y muchos de sus cuadros militantes se incorporaron a la gestión del gobierno de la Provincia de Buenos Aires, encabezada por Domingo Mercante. Sin embargo, la identidad previa de sus militantes se mantuvo, al punto que muchos se referían al "gabinete forjista» del gobernador.

Los vínculos de FORJA con el APRA han sido mencionados en distintos estudios; se ha afirmado, incluso, que FORJA puede ser considerada un «remedo local del APRA». Ese parentesco podría atribuirse a la influencia de Gabriel del Mazo, cuya cercanía con Haya de la Torre y el APRA es ampliamente reconocida. Sin embargo, hasta ahora no se ha difundido el contenido de las cartas entre ambos dirigentes, lo cual permitiría reponer algo más de los vínculos entre las dos organizaciones. Los documentos o referencias que hemos encontrado para reconstruir esas redes han sido más bien escasos. En ese contexto, la trayectoria de Capelli ofrece un testimonio que hasta ahora no ha sido explorado.

Jauretche (1962). En FORJA, reconocía la influencia aprista en la organización, aunque procuraba señalar sus diferencias: «la influencia del APRA fue más que nada la de sus análisis generales sobre el fenómeno imperialista, porque en la misma medida que APRA expresaba una visión peruana, podía ser una de las tantas fugas de la concreta realidad rioplatense, que se iba perfilando a nuestros ojos con características completamente distintas». F.O.R.J.A y la Década Infame, Buenos Aires. (Ediciones Coyoacán, p. 56).

Respecto de los vínculos del APRA con el peronismo, el tema no ha sido sistemáticamente abordado dese el análisis histórico. Por un lado, estudios más ligados a perspectivas sociológicas han ubicado al APRA como parte de las experiencias "populistas» en América Latina, y por lo tanto han generado comparaciones con el peronismo. Desde otros puntos de vista, y partiendo de la inspiración aprista de FORJA, se ha destacado la influencia del aprismo a través del aporte forjista a la ideología del peronismo.

Townsend (1989), contribuye a asentar esta interpretación a través de la reseńa de estudios sobre la presencia del APRA que prologan el libro de Percy Murillo Garaycochea: «En la Argentina peronista y postperonista al rastrearse las influencias externas que contribuyeron a la heterogénea conformación ideológica de ese movimiento popular, se coincidió en señalar a FORJA, plantel político de brillantes figuras como recipendaria, hacia 1935, de ideas nacidas de la cantera aprista». «Sobre el APRA y su historia», en: Townsend Ezcurra, A., 50 años de aprismo. (Memorias, ensayos y discursos de un militante, Lima, 1989, p.175). 
Por otro lado, es posible extraer algunos datos de diversos testimonios, que reponen algunos acontecimientos y relaciones entre el aprismo y el peronismo, y que permiten analizar las cercanías, distancias y tensiones entre ambos espacios. Sin pretensión de alcanzar la exhaustividad que sería necesaria para realizar un estado de la cuestión sobre el tema, mencionaremos algunas referencias que hemos podido rastrear.

El ascenso y la victoria electoral del peronismo en Argentina resultaron contemporáneas a la organización del Frente Democrático en Perú, que llevó a la presidencia a Bustamante y Rivero con apoyo del aprismo. En ese momento, que coincidía también con el escenario de posguerra, el APRA había alcanzado acuerdos con distintos sectores políticos para participar por primera vez de un gobierno. Desde comienzos de la década del cuarenta, frente al ascenso internacional del nazismo, el discurso de Haya había moderado las consignas de lucha contra el imperialismo yanqui, que conformaban el núcleo de los diagnósticos e iniciativas del APRA en las décadas anteriores. En ese contexto, Haya de la Torre destacaba los rasgos autoritarios del liderazgo de Perón y veía al peronismo como una variante del fascismo. Esa caracterización se correspondía con las posiciones de la mayoría del arco político opositor a Perón en Argentina, entre los que se encontraban buena parte de los socialistas, y entre ellos muchos de los viejos dirigentes o militantes que habían estado cerca del APRA. Sin embargo, esa caracterización no era una posición homogénea dentro del aprismo, y es posible identificar diferentes posturas sobre el peronismo y la figura de Perón.

Recordemos que, tras el levantamiento del 3 de octubre 1948 y los acontecimientos que derivaron en el Golpe de Estado que llevó al gobierno a Odría, muchos dirigentes del APRA fueron encarcelados o debieron partir nuevamente al exilio, y Haya de la Torre comenzó su largo periplo como refugiado en la embajada de Colombia en Lima. En ese contexto, algunos dirigentes apristas consideraron la posibilidad de organizar un plan militar para ingresar a Perú y derrocar a Odría. Dicho plan sería apoyado y financiado en parte por el gobierno argentino y se sostenía también en las relaciones con el gobierno boliviano del MNR. Diversos testimonios narran los encuentros entre Perón y dirigentes del APRA en Buenos Aires en 1952, que al parecer estuvieron cerca de concretar el mencionado plan. Si bien no fue el motivo de su frustración, Haya de la Torre, con menor conocimiento de la trama por su aislamiento, y Luis Alberto Sánchez, cuestionaban el acuerdo y los vínculos de los exiliados con el peronismo. Esa posición se sostenía en la desconfianza sobre el presidente argentino, en cuya caracterización persistía la imagen negativa impregnada de un distanciamiento ideológico y político entre el aprismo y el peronismo. Tal como recuerda Sánchez:

Haya rechazaba a Perón por ser un autócrata teatral, como lo dice en una carta de Mayo de 1953; por convertir en caudillaje militar el gobierno de la Argentina, por haber sido enemigo de la Reforma Universitaria, que prácticamente destruyó en 1946 
y por haber pretendido crear para sí un caudillaje hispanoamericano. (Sánchez, 1982, Op. Cit., p. 16).

Manrique (2009), sostiene la hipótesis de que el principal motivo de la oposición de Haya y Sánchez al acercamiento a Perón era la competencia por el liderazgo continental del antiimperialismo: «Luis Alberto Sánchez rechazaba cualquier acuerdo con Perón, según dice en su texto [Testimonio personal], porque este era un dictador. Sin embargo, en su testimonio, entre líneas, se insinúa otro motivo más de fondo: a Sánchez se le hacía intolerable la pretensión de Perón de constituirse en el líder del antiimperialismo latinoamericano, papel que él consideraba reservado para Haya de la Torre». «Usted fue aprista». "Bases para una historia crítica de APRA», (p. 125).

Más allá de los hechos que rodean el plan, resulta posible encontrar caracterizaciones del peronismo realizadas por apristas, que se sostienen sobre el señalamiento de afinidades ideológicas, y que en algunos casos constituyen verdaderas reivindicaciones de la experiencia argentina. Por ejemplo, frente a la difusión del acercamiento de Manuel Seoane al peronismo, en el marco de las gestiones ligadas a la conspiración, un artículo publicado en Argentina no sólo no desmentía los vínculos, sino que enfatizaba el apoyo del aprismo al peronismo:

Los socialistas de México y los trotzkistas de París acaban de publicar conjuntamente un duro ataque al aprismo por el apoyo moral que presta al movimiento emancipador que encabeza el general Perón. Acusan a Manuel Seoane - líder aprista - de abandonar la línea democrática -demoliberal, según ellos-, y de respaldar la metodología «fascista» del actual presidente argentino. [...] «Ya no creemos - dicen- en aquel antiimperialismo del Apra, que tantas esperanzas despertara en los pueblos morenos de América del Sur; ahora ingresa en una política oportunista, cuyos resultados previsibles favorecerán a los enemigos de las Naciones Unidas» (Carnero, 1953, p.5).

En este artículo, titulado Por qué los apristas apoyan a Perón, algunos sectores apristas expresaban apoyos al peronismo eludiendo cualquier referencia elíptica o tramas secretas. Esa reivindicación se sostenía en una crítica a quienes consideraban, como Haya de la Torre o Luis Alberto Sánchez, que el peronismo conformaba una experiencia diferente a las tradiciones en la que se inscribía el APRA:

El antiimperialismo no es una postura lírica ni menos grito destemplado para risa de los jerarcas de la banca y el comercio; es ante todo, una decisión, y en esto la actual Argentina ha dado muestras de contraposición económica que duele y enferma a los señores del Wall Street. [...] La libertad ya no es mero postulado lírico, al que hay que 
defender con la voz engolada; es plasmación económica, que se fortalece quitando al capitalismo -imperialista y abusivo- sus fáciles mercados y transformándolos en pan, tierras, trabajo, felicidad para los trabajadores de la ciudad y del campo. Y eso es lo que el aprismo quiere y lo que Perón está dando a su pueblo, y por eso estamos con él.

Por último, la afinidad entre el APRA y el peronismo se afirmaba en el carácter de masas de ambas experiencias políticas, lo que las ubicaba en el mismo espacio:

Finalmente, camaradas trasnochados, nosotros nos entendemos con el presidente argentino porque tenemos qué ofrecer: somos un partido de masas, con un capital de treinta años de insobornables luchas. Tenemos qué ofrecer para inclinar la victoria a nuestro favor. Nosotros no somos cuatro gatos lamiendo a la luna; somos gente que tiene raíces en América y que tiende su generosa mano al gran pueblo argentino que encarna Perón y su justicialismo. Ellos y nosotros volvemos a juntarnos para arrojar de nuestro suelo a los nuevos conquistadores.

Este tipo de expresiones que apuntalaban las relaciones entre el APRA y el peronismo, fundadas en una identidad compartida, también se expresaban del lado argentino, tal como se desprende de los comentarios sobre el reencuentro de algunos sectores cercanos al peronismo con Manuel Seoane en Chile, en ocasión de un viaje de Perón:

Uno de los más gratos reencuentros fue el de Manuel Seoane, cuya prestancia de luchador infatigable y esclarecida visión de la realidad indoamericana lo ha colocado en el primer rango entre las huestes en exilio forzoso. Existía con él una permanencia de vínculos afectivos e ideológicos que no ha envejecido con los años, como no ha decaído el propio líder en las cualidades de su hombría civil.[...] Fue un reencuentro emotivo porque a través de él repasamos durante pocas horas los densos capítulos de una existencia civil que nos ha identificado al servicio de afanes comunes. (Pedro, 1953, p.7).

Más allá de estos testimonios, que permiten identificar afinidades, es interesante advertir que las observaciones realizadas por algunos altos dirigentes apristas sobre el peronismo ofrecen también imágenes mucho más matizadas que la simple condena a una experiencia caracterizada como «fascista».

Sánchez (1987), en esos términos recuerda posteriormente la figura del presidente argentino, al referirse a los acercamientos propiciados por Armando Villanueva: «...encandilado por el ansia de ver libre a Víctor Raúl y por las habladurías peronescas al respecto, él también se había dejado tentar por una posible ayuda del Perón, el Mussolini gauchesco». (Testimonio personal. p. 190, citado en Manrique, Op. Cit., p. 129). 
Armando Villanueva reconstruye buena parte de la trama de contactos con Perón, de donde pueden extraerse algunas de sus impresiones. Sobre la figura del presidente argentino, señala: «No se puede poner a Perón en el mismo costal que a los dictadores de facto. No era lo mismo, como quedaría demostrado en la historia futura». Algunas de sus observaciones muestran cierta admiración por la figura del líder argentino: «Irradiaba poder. Impactaba. Tenía una gran capacidad para atraer a la gente. En eso se parecía a Víctor Raúl».

La narración de Villanueva sobre los encuentros con Perón es muy interesante y está plagada de detalles y anécdotas. De allí surge el relato en el que el presidente argentino menciona su conocimiento e interés por el aprismo: «La conversación empezó con un saludo. Nos recibía con mucha satisfacción. 'Quiero decirles que durante muchos años el libro de Haya de la Torre El Antiimperialismo y el APRA, fue mi libro de cabecera». Villanueva también recuerda que Perón conocía la tesis de Luis Heysen sobre la situación del agro argentino que había escrito como trabajo final de su carrera de agrónomo en la Universidad Nacional de La Plata.

El vínculo con Perón, que recrea Villanueva a través del relato de esta trama de encuentros, muestra la camaradería y las afinidades que rodeaban los planes conspirativos. Incluso, y más allá de que Perón estaba al tanto de las críticas del líder del aprismo, Villanueva menciona el apoyo del gobierno argentino a la conformación de un Comité por la Libertad de Haya de la Torre. Entre los problemas que seńala se encontraba la oposición de los socialistas argentinos, que eran fuertemente antiperonistas: «Los viejos socialistas mantenían una línea antiperonista pero eran nuestros amigos. Viejos amigos. Pertenecían a una línea formal que se podía reflejar en la precavida actitud de Sánchez, al no ir al encuentro con Perón; o en la de Haya, entonces en la distancia de su asilo. Los socialistas sostenían que Perón era un dictador.»

Pero Villanueva advierte también sobre los pequeños grupos de socialistas disidentes que se habían acercado al peronismo: «Ciertos socialistas como el Doctor Dickman, Juan Unamuno y otros líderes daban su apoyo a Perón porque con él venían las reformas».

Acaso esas mismas tensiones atravesaban internamente al aprismo. El testimonio de Villanueva afirma la evidente cercanía que existía entre buena parte de los apristas exiliados y el peronismo. No sólo porque Perón aparecía como apoyo y estratega de un plan conspirativo, sino por las mencionadas afinidades y cercanías que encontraban entre el aprismo y la experiencia peronista.

Es posible rastrear también algunas relecturas posteriores realizadas por referentes del APRA, que aportan balances sobre el peronismo. Los recuerdos de Andrés Townsend Ezcurra, que pasó una década exiliado en Argentina, reponen algunas de sus perspectivas. En sus memorias, al referirse a la figura del líder del peronismo, observa su 
liderazgo como resultado de la escasa sensibilidad de otras expresiones de izquierda ante las demandas populares: «Carismático, elocuente, contradictorio, habilísimo, con un profundo sentido para percibir los recónditos sentimientos e instintos populares, Juan Domingo Perón fue fruto de muchas frustraciones argentinas y una fe de erratas de todas las cometidas por los dirigentes democráticos y de izquierda argentinos en el siglo XX». (Townsend, Op. Cit., p. 65).

$\mathrm{Al}$ referirse al lugar del peronismo en la historia argentina, su caracterización está lejos de la impugnación: «El primer cambio político importante acontece a comienzos del siglo XX, cuando una generación de argentinos de clase media y de progenie europea, rompen el esquema de la república oligárquica y llegan al poder con el radicalismo. El segundo cambio -la segunda revolución- ocurre en 1945 cuando Perón moviliza a los sectores más pobres de una sociedad desigualmente enriquecida, los 'descamisados', abandona el módulo feudal de la gran estancia ganadera y fomenta una rápida industrialización». (Townsend, Op. Cit., pp. 65-66).

Estos datos y anécdotas no aspiran a sostener conclusiones definitivas sobre las relaciones entre el aprismo y el peronismo; sirven, sin embargo, para observar las tensiones y contradicciones de un vínculo que aún no fue suficientemente reconstruido. Dentro de ese panorama, la biografía de Francisco Capelli también abre una ventana para asomarse al tema.

\section{Capelli se encuentra con el aprismo}

Francisco José Capelli era oriundo de la ciudad de Mar del Plata, ubicada en la costa atlántica argentina. Había nacido en 1916, justamente el año en el que la Unión Cívica Radical accedía por primera vez al gobierno a través del triunfo de Hipólito Yrigoyen. Durante sus estudios secundarios, un profesor del Colegio Nacional de Mar del Plata le había acercado algunas lecturas sobre el aprismo. Tal vez ese antecedente haya pesado en la decisión de trasladarse a la ciudad de La Plata para estudiar Derecho en la Facultad de Ciencias Jurídicas y Sociales. La Universidad Nacional de La Plata era ya reconocida por su impronta reformista. Alfredo Palacios, Gabriel Del Mazo y Carlos Sánchez Viamonte, entre otros protagonistas del movimiento y activos referentes del antiimperialismo latinoamericano, eran Profesores en los distintos claustros universitarios. La misma impronta animaba la vida estudiantil. Durante la década del veinte el aprismo había logrado insertarse en las redes del reformismo argentino, en general, y platense, en particular. Testimonio de ello había sido la elección de Luis Heysen como presidente de la Federación Universitaria de La Plata entre 1926 y 1928. 
Según Capelli, (1938), estos datos surgen de su declaración ante el interrogatorio realizado por un oficial de la Policía de la Provincia de Buenos Aires. La detención de Capelli se produjo en el marco del seguimiento a la militancia aprista argentina, realizada bajo la órbita de la Sección de Orden Social de la Policía. Hemos reconstruido las actividades de las organizaciones a partir del documento policial, en: Sessa, Leandro,“ «Sólo el Aprismo Salvará a la Argentina». Una reconstrucción de la militancia aprista en Argentina a fines de la década de 1930». ( pp. 37-65).

Townsend Ezcurra recuerda el clima de confraternidad latinoamericana que aún pervivía en la década del treinta en la Facultad de Ciencias Jurídicas de la UNLP, a donde había realizado estudios durante sus años de destierro en Argentina. Entre los nombres que menciona figura Capelli:

En aquellos años La Plata comenzó a ser un centro clásico de estudios para los latinoamericanos. Algunos como Jorge Frías Caballero, boliviano de nacimiento, ha hecho gran carrera de magistrado argentino, Francisco Pagán Rodríguez, puertorriqueño, autor del código penal de su isla. Francisco Capelli, de Mar del Plata, los hermanos Samuel y Raúl Amaral, platenses y fervorosos integracionistas (Townsend, Op. cit., p. 77).

Raúl Amaral había organizado en 1936 un Sindicato Aprista de Estudiantes (SAE), junto con sus compañeros del Colegio Nacional de La Plata, Omar Rizzo y Alfredo Castro. Capelli se había sumado en 1937, atraído por la propuesta de Amaral.

La actuación del Sindicato parece haberse orientado principalmente a la participación en distintos espacios universitarios, con escasas repercusiones en sus primeros años. Recién en 1938 la revista Claridad daba difusión a la existencia de la organización.

Entre el estudiantado de la Universidad Nacional de La Plata y de sus institutos anexos, el Colegio Nacional y el Liceo de señoritas, se ha constituido un Sindicato Aprista de Estudiantes, que incluye también representaciones de otras escuelas nacionales. El propósito de la nueva institución ha quedado fijado dentro de la línea general que informa al movimiento de liberación de los países de América Latina del capitalismo imperialista, y por otros postulados sociales y universitarios que se contemplan en los puntos siguientes:

1.Trabajar por la unificación real del estudiantado indoamericano;

2. Sostener, en todos los campos, los postulados reformistas de la revolución universitaria del año 1918;

3. Campańa pro-organización de sindicatos de estudiantes secundarios;

4. Acción a favor de la rebaja de aranceles; 
5. Propender a la reforma de los planes de estudios primarios, secundarios y universitarios;

6. Creación de centros culturales para la capacitación integral de estudiantes.

Para entonces, Capelli ostentaba el cargo de Secretario de Redacción del SAE y mantenía correspondencia con Luis Alberto Sánchez. También era el encargado de las relaciones con el Partido Aprista Argentino (PAA), que había nacido, al parecer de manera independiente, en la Ciudad de Rosario.

En una carta a Sánchez, Capelli advertía sobre los vínculos que los miembros del sindicato aprista sostenían con grupos de orientación comunista.

En el orden político hacemos transitoriamente buenas migas con los comunoides que como Ud. sabe dirigen y controlan el movimiento estudiantil argentino en estos momentos; particularmente en ésta su hegemonía es absoluta; por estas razones, y en consideración a nuestra posición determinante minoría, es que trabajamos paralelamente a ellos en el orden estudiantil reformista. (Archivo DIPBA, mesa C, Legajo 62, Carta de Capelli a Sánchez, junio de 1938).

Esta aclaración parecía indicar cierta cercanía del aprismo argentino con el comunismo, que contrastaba con las posiciones más férreamente anticomunistas de los dirigentes peruanos. Podría tratarse de un dato menor, si no fuera porque un año después Capelli será parte del grupo universitario forjista que, junto con el comunismo, logrará hacerse del control de la FUA.

Pero antes de ese paso, que comenzaría a distanciar a Capelli del aprismo, el estudiante marplatense intervenía activamente como militante de un espacio aprista dentro del medio estudiantil de la Ciudad de La Plata. Durante el año 1938 fue uno de los impulsores del Seminario Indoamericano Mariano Moreno. Se trataba de un espacio del que participaban estudiantes de distintos países del continente, y que se proponía la difusión del pensamiento y la cultura indoamericana, con fuerte influencia aprista. Si bien el Seminario era «auspiciado» por Carlos Sánchez Viamonte y Ataúlfo Pérez Aznar, el primero socialista y el segundo radical, la injerencia aprista puede constatarse a través de la participación de los miembros del SAE y de Marcial Gayoso. Éste último, peruano y cercano a Manuel Seoane, había participado del Comité Aprista Peruano de Buenos Aires, antes de trasladarse a La Plata. El único comunicado público del Seminario estuvo referido a la situación de Luis Heysen:

Al dedicar Claridad, de Buenos Aires, parte de un número al gran luchador Luis Heysen, el Seminario Indoamericano Mariano Moreno, que agrupa a los estudiantes de Puerto Rico, Venezuela, Guatemala, Bolivia, Chile, Argentina y Perú, hace llegar 
su mensaje de adhesión. Y lo hace obedeciendo a las ideas fundamentales de su declaración de principios. «Por la libertad y la vida de Haya de la Torre y Luis Heysen», (Revista Claridad, abril de 1938).

Capelli parece haber estado dedicado esos años más a la organización política que a la escritura. Su único texto de 1938 corresponde a una publicación universitaria y está firmado con el seudónimo Franjoc. Allí Capelli expresa ya una fuerte crítica al liberalismo para explicar los problemas de Indoamérica:

De norte a sur y de este a oeste, salvo muy raras veces, indoamérica fue gemido — de moribundo, no de recién nacido - y su hombre una ficción, una burlesca ficción [...] al hombre indoamericano se le impusieron siempre los roles de bufón, pillastre, traidor y fornicador de indefensas mujeres. Más que hombre fue bestia. Y fue bestia porque así se justificaba la 'civilización' que nos trajeron los ingleses y los yanquees, hurtándonos nuestras riquezas, imponiéndonos su política, que es la peor de las políticas, la del hipócrita liberal, que es señor de horcas y cuchillos. «El hombre de indoamerica». (Reforma, julio de 1938).

El texto de Capelli define en torno del antiimperialismo una fuerte crítica a la política entendida en los términos del liberalismo. En el aprismo había encontrado, al parecer, una respuesta a esas inquietudes, tal como se desprende de la descripción realizada frente a un interrogatorio policial:

Que el Partido Aprista en ciertos aspectos tiene contactos con el fascismo pues es partidario del corporativismo. Que ignora el porqué de la organización, división y sub división de la acción y movilización aprista, que en cierto modo se asemeja a la forma de trabajar del comunismo, pero cree personalmente que haya adoptado ese sistema de trabajar por resultar más práctico.

Probablemente Capelli sabía que la comparación con el fascismo y la justificación o explicación de las posibles semejanzas con el comunismo, eran una forma de aliviar su situación frente al Oficial de la Policía que lo interrogaba (en un momento en que existían restricciones legales a la actividad del comunismo en Argentina). Más allá de esto, resulta interesante reparar en los aspectos que hacían verosímil ese tipo de comparación. (Archivo DIPBA, Op. Cit., Julio de 1938). 


\section{Capelli se encuentra con Forja}

Sólo un año después de las iniciativas apristas que lo habían tenido como protagonista, Capelli fue elegido representante por la Federación Universitaria de La Plata (FULP) en la Federación Universitaria Argentina (FUA), como miembro de la Organización Universitaria Forjista (OUF), grupo conformado también por Miguel López Francés y René Orsi, y que había sido impulsado por Raúl Scalabrini Ortiz. Como representante de esa incipiente organización, y con el apoyo del comunismo, Capelli se alzó con el cargo de presidente de la FUA. Durante su gestión sostuvo una posición neutralista frente al conflicto europeo, en la línea establecida por la dirección central de FORJA. Dicha posición, dentro del movimiento estudiantil, buscaba frenar el avance de las posturas aliadófilas de los dirigentes socialistas

La dirección de la FUA estuvo atravesada durante esos años por una relación ambigua con la tradición del reformismo universitario. Por un lado, la Reforma del 1918 era explícitamente revindicada, aludiendo a los principios antiimperialistas y latinoamericanistas que la habían inspirado, y por su gesto emancipador que había movilizado a la juventud; pero al mismo tiempo se consideraba desvirtuado su legado. La organización universitaria forjista de Córdoba, por ejemplo, expresaba el fracaso de la Reforma en los términos de una «tradición nacional» ausente en los claustros universitarios.

Reivindicamos el concepto auténtico de reforma: voluntad de destino de la Nación dentro de la conciencia de América. La concebimos como una emancipación de los valores propios. Es eso o no es nada [...] la misión de la Universidad es crear una conciencia superior del país. En este sentido ha fracasado [...] iniciamos la marcha bajo el signo de la montonera, que irrumpe en los claustros. Ha llegado la hora del federalismo. Recogemos la bandera plebeya de las muchedumbres inciviles. Venimos a derrumbar los ídolos del paganismo científico-legalista, al dogma del derecho importado oponemos el dogma de la tierra; al concepto abstracto de la civilización del mundo, la realidad telúrica de América (Scenna, 1983, p. 271).

Los forjistas universitarios debieron lidiar con un nuevo contexto desde junio de 1943, cuando se produjo un Golpe de Estado impulsado por sectores nacionalistas del ejército. El apoyo de FORJA, aunque no exento de reparos, ponía de manifiesto un decidido distanciamiento de las conexiones iniciales con alguna tradición liberal. Sin embargo, Capelli y la FUA asumieron una decidida oposición a la irrupción del nacionalismo católico en la Universidad, representada por la intervención de Jordán Bruno Genta en la Universidad del Litoral, y también se manifestaron en contra de la presencia del gobernador Manuel Fresco, de orientación conservadora, en las aulas universitarias. 
El forjismo intentaba así sostener una línea neutralista ante el conflicto internacional, definiendo un lugar entre la izquierda y los sectores liberales, pero al mismo tiempo opositora a los grupos católicos y nacionalistas que gobernaban desde 1943.

Los estudiantes se manifestaron vaciando abruptamente el salón en donde iba a hacer uso de la palabra el gobernador de la Provincia. La noticia fue recogida por el periódico Reconquista. Allí Capelli expresaba: «la actitud asumida es una reafirmación del sentir reformista, democrático y anti-imperialista de los universitarios de La Plata, que han estado y están, en las avanzadas que luchan por la emancipación económica, política y cultural de nuestra patria». (En Reconquista, p. 4).

Capelli parece haber transcurrido esos años, entre 1939 y 1943 volcado a las actividades que le demandaban la militancia estudiantil. El único texto de su autoría que conocemos es el prólogo a una edición promovida por FORJA de la obra Vida de Chacho, de José Hernández. Allí Capelli sostiene las posiciones del nacionalismo revisionista. Sin embargo, resulta interesante reparar en las ambiguas referencias a la figura de Sarmiento y a los caudillos del siglo XIX:

Es preciso revisar nuestro pasado, pulsar a fondo los valores que jugaron en la construcción de nuestros pilares fundamentales de la nacionalidad. Es imperioso conocer la verdad íntegra cruda de nuestro espíritu nacional [...] Se trata de comprender que, si bien Sarmiento fue un inspirado patriota, también tuvo enormes errores. Que los caudillos, esas figuras que se nos enseñara a odiar y a despreciar, si bien cometieron errores, también fueron genuinos y sacrificados patriotas. Que si el gaucho, figura admirada y respetada como soldado en las huestes de San Martín, Paz, Belgrano y Güemes, fue reconocido como valor humano laborioso, sacrificado y trabajador, mal pudo ser como se pretendió enseñarnos, elemento retrógrado, indisciplinado, sanguinario y ladrón cuando milita en las filas gauchas de los Quiroga, los Ramírez, los Peñaloza y los López. [...] La Vida del Chacho [...] es uno de los tantos escritos que contradicen el abecedario antinacional que se nos enseñara a deletrear (Capelli, 1943, p. 5).

En un año, Francisco Capelli pasó de la militancia en el aprismo a transformarse en un dirigente forjista universitario. Ese sería el comienzo de una promisoria carrera, que lo llevaría a organizar el forjismo en Mar del Plata, y finalmente a presidir FORJA, hasta su disolución en 1945.

Sin embargo, Capelli conservaría en su tránsito hacia FORJA algo más que su conocimiento de los problemas de Indoamérica. Sin conocer la militancia aprista de Capelli, la investigadora Delia García se ha aproximado al problema de las tradiciones políticas que confluyen en FORJA, a través del análisis de la filial marplatense de dicha 
organización. En su estudio advierte que el forjismo marplatense se constituyó en torno de Francisco Capelli, quien provenía de la militancia en el reformismo de la ciudad de La Plata, y había llegado a FORJA bajo la influencia de Gabriel del Mazo. García observa que los elementos ideológicos que provenían de la cultura política de la militancia universitaria de Capelli (a lo que agregaríamos nosotros sus vínculos con el aprismo) influyeron en sus posiciones y en las tensiones internas dentro del forjismo de Mar del Plata. Capelli sostenía una perspectiva política que depositaba en los sectores profesionales las expectativas de liderazgo de un frente de liberación nacional. Esta posición era sostenida por la línea interna del forjismo marplatense que encabezaba, cuya denominación era, significativamente, Frente de Trabajadores Manuales e Intelectuales (FTMI).

\section{Forja se encuentra con el peronismo}

Disuelta formalmente la organización frente a la emergencia del fenómeno peronista, el forjismo, sin embargo, siguió siendo un grupo reconocible, fundamentalmente a partir de la integración de muchos de sus referentes en el gobierno de la Provincia de Buenos Aires. Sin embargo, los forjistas tuvieron también cierto protagonismo en la organización del peronismo provincial, en donde participaron y disputaron espacios en torno del recientemente formado Partido Peronista (PP) de la Provincia. Francisco Capelli, desde su ciudad natal, fue uno de los dirigentes que participó de la organización del peronismo marplatense. Capelli era el referente de una de las facciones, que quedó relegada luego de las elecciones internas realizadas en 1947. El "capellismo» estaba enfrentado con la línea encabezada Juan José Pereda, quien accedería a la intendencia. La derrota expresaba la condición minoritaria del forjismo dentro del naciente peronismo, que tenía sus cimientos en las estructuras de organización sindical y en la articulación, en el caso de Mar del Plata, con la Delegación de la Secretaría de Trabajo y Provisión Social, entre otros actores.

Tal vez debido a ese lugar relegado, más allá de que algunos de los concejales elegidos respondían a su "facción», Capelli se integró en 1948 al "grupo forjista» de la gestión provincial. Allí ocupó el cargo de Subsecretario de Previsión. Se trataba de un área del Ministerio de Hacienda, que cumplió un rol clave en el impulso de las políticas de Turismo Social en la Provincia. Desde allí

Capelli impulsó algunas iniciativas para apuntalar el desarrollo del acceso al ocio de sectores trabajadores, en donde la ciudad de Mar del Plata cumplía un papel relevante. De esos años data el único libro de su autoría, en el que Capelli despliega un análisis de los antecedentes históricos del Turismo Social, para enmarcar algunas de las iniciativas que impulsaba desde su área.38 
Capelli se transformó en un funcionario relevante del gobierno provincial, pero relegado en el armado del peronismo marplatense. Así, su carrera política dentro del peronismo sufriría la misma suerte del forjismo. Desde 1952, y en el marco de una fuerte campaña de desprestigio dentro de las filas del peronismo, el grupo forjista iría perdiendo terreno. Finalmente, el desplazamiento de Mercante del gobierno Provincial terminó por marginarlos, e incluso algunos de sus referentes fueron perseguidos y encarcelados.

\section{Consideraciones finales}

Capelli fue expulsado del Partido Peronista en 1953. La decisión expresaba el retroceso de la autonomía de los espacios de participación sobre los que se había gestado la experiencia peronista. Pero fundamentalmente era la consecuencia del conflicto que había expulsado del gobierno a los grupos referenciados con el forjismo, y específicamente a quienes participaban del gobierno provincial encabezado por Mercante.

En esa trayectoria del forjismo, y específicamente de quien había impulsado una experiencia aprista en Argentina, se condensan algunas paradojas, que quisiera incorporar al final de este trabajo como ideas e hipótesis para pensar ciertos rasgos del aprismo y del peronismo.

Si bien sería exagerado extraer conclusiones definitivas de los elementos de esta biografía, el itinerario político e intelectual de Capelli permite identificar ciertas tensiones que recorren la historia de ambas experiencias, atravesadas por idearios que podríamos llamar «nacional-populares».

Si bien es posible encuadrar al aprismo y al peronismo dentro de una misma familia de experiencias, afinidad detectada en los comienzos de los años cincuenta por algunos sectores del aprismo, y reconocida por el propio Perón, sus trayectorias posteriores han tendido a borrar esas cercanías a partir de operaciones en sentidos opuestos. El aprismo, o al menos algunas de sus más visibles vertientes «oficiales», profundizó su inscripción en una tradición política liberal-democrática, reactiva a las experiencias revolucionarias y nacionalistas en el continente. Esa decisión relegó la tensión entre el marxismo, el nacionalismo y el liberalismo, enmarcada en una perspectiva revolucionaria, que caracterizó las primeras décadas del APRA. Mientras tanto, el peronismo tempranamente tendió a romper sus conexiones con los antecedentes que lo acercaban a experiencias previas, por ejemplo, algunas expresiones del antiimperialismo latinoamericano, a partir de una operación orientada a la construcción de una memoria centrada en la figura de Perón y su vínculo con los trabajadores desde 1945.

Esos dos recorridos tendieron a deformar la evidente convivencia de distintas tradiciones y culturas políticas sobre las cuales se construyeron diagnósticos y se ofrecieron soluciones al «problema nacional». 
Cuando el aprismo intentó despojarse de los elementos que lo ligaban a un nacionalismo popular con rasgos antiliberales, algunos sectores buscaron reencauzarlo a través de señalar sus afinidades con el peronismo. Al mismo tiempo, el forjismo, y el itinerario de Capelli, expresaban las conexiones con ciertos elementos de una cultura política que se reconocía inscripta en redes del antiimperialismo, pero no necesariamente renegaban de la tradición socialista-liberal. En la ambigua relación establecida por Capelli con el reformismo universitario y la figura de Sarmiento, parece desplegarse cierta expectativa en el rol de los sectores ilustrados y de la educación, como herramientas para despertar las conciencias nacionales atrapadas por el imperialismo. Acaso esa incómoda posición era la misma que expresaba Townsend Ezcurra al referirse al lugar del aprismo en la Argentina de los treinta:

Los comunistas, al ver desdeñada su propuesta frentepopulista, arreciaron sus ataques. Por su disciplina, por sus símbolos, por sus cantos, el APRA era «fascista». Lo era también por su devoción colectiva por el jefe, Haya de la Torre [...] Por su parte la derecha argentina nos tildaba de comunista y el día que el Comité inauguró su local, en Perú 443, un grupo de la Legión Cívica, organización paramilitar fascista trató, sin conseguirlo, de disolver el acto. Atacados por la izquierda, atacados por la derecha ¿Cuál era la justa posición del Partido? ¿Cuál era la mía como joven militante? (Townsend, Op. cit., p. 74).

La empatía de Capelli con ese lugar lo había llevado a acercarse al aprismo en sus primeros años de militancia.

El antiimperialismo navegó en América Latina dentro de distintas y contrastantes tradiciones políticas. La biografía de Capelli ofrece un testimonio de sus recorridos, dificultades y tensiones para transformarse en el eje de una construcción política en Argentina. Acaso sea ese, también, un nudo problemático para la historia y la historiografía del APRA.

\section{Referencias bibliográficas}

Archivo DIPBA, Mesa C, Legajo 62, Carta de F. Capelli a Luis A. Sánchez, junio 1938.

Archivo DIPBA, Op. cit., Declaración de F. Capelli, julio de 1938.

Bergel, M. (2006-2007). Manuel Seoane y Luis Heysen: el entrelugar de los exiliados apristas peruanos en la Argentina de los veintes. Políticas de la Memoria 6/7, Buenos Aires.

Bisso, A. (1999). La unión democrática y los usos del antifascismo: las utilidades políticas de un discurso sociocultural, Cuadernos del CISH,4(5):199-213. Disponible en: http://www. memoria.fahce.unlp.edu.ar/art_revistas/pr.2804/pr.2804.pdf 
Bruno, P. (2016). «Biografía, historia biográfica, biografía-problema», Prismas, Revista de Historia Intelectual $N^{\circ} 20$, Bernal, Editorial de la Universidad Nacional de Quilmes: 267272. Disponible en http://www.unq.edu.ar/catalogo/393-prismas-n-20-/-2016.php

Capelli, F. (1943).«Palabras aclaratorias a La vida de: "El Chacho» por José Hernández». Buenos. Aires, Cuadernos Forjistas-Núcleo Mar del Plata, p. 5.

Carnero, G.(1953). «Por qué los apristas apoyan a Perón», Periódico Argentina de Hoy, 1 de julio, p. 5.

Ciria, A. (1971). Perón y el justicialismo, Buenos Aires: Siglo XXI.

Cossío del Pomar, F. (1961). Biografía de Haya de la Torre. México: Editorial Cultura.

Chanduvi, L. (1988). El APRA por dentro. 1931-1957. Lo que hice, lo que vi, lo que sé. Lima: Perú.

Enríquez, L. (1951). Haya de la Torre, la estafa política más grande de América Latina. Lima: Ed. Del Pacífico.

Ercilla, S. (1954 [1934]). Haya de la Torre y el APRA. Santiago: Ed. del Pacífico.

García, D. (2006). FORJA en la conformación del peronismo. El caso de Mar del Plata. Disponible en: http://historiapolitica.com/datos/biblioteca/http:/garcia.pdf.

García, I. (2009). Revolucionaria peregrina: Magda Portal, el exilio y el APRA como partido continental, 1926-1945, Congreso Internacional de Americanistas, México.

González, M. (2007). Poética e ideología en Magda Portal, Lima, Instituto de Estudios Peruanos. Disponible en: https://iep.org.pe/actividades/presentacion-del-libro-poetica-e-ideologiaen-magda-portal-otras-dimensiones-de-la-vanguardia-en-latinoamerica/

Halperin, T. (2003). La Argentina y la tormenta del mundo. Ideas e ideologías entre 1930 y 1945. Buenos Aires, pp. 150-151.

Jauretche, A. (1962). F.O.R.J.A y la década infame. Buenos Aires: Ediciones Coyoacán, p. 56.

Klarén, P. (1970). La formación de las haciendas azucareras y orígenes del APRA. Lima: MoncloaCampodónico Editores Asociados.

Mackinnon, M. y Petrone, M. (1998). Populismo y neopopulismo en América Latina. Buenos Aires: Eudeba.

Manrique, N.(2009). Usted fue aprista. Bases para una historia critica de APRA. Lima: PUCPCLACSO, p.125.

Martuccelli, D. y Svampa, M. Las asignaturas pendientes del modelo nacional popular.

Panella, C. (Comp.), El gobierno de Domingo A. Mercante en Buenos Aires (1946-1952). Un caso de peronismo provincial, Archivo Histórico de la Provincia de Buenos Aires, 2005, pp. 297- 320 .

Pedro, J. (1953). Fraternidad en el exilio. Periódico Argentina de Hoy, (23), marzo, p. 7.

Quiroga, N. (2004). La formación del Partido Peronista en Mar del Plata: articulación horizontal y articulación vertical (1945-1955), Boletín del Instituto de Historia Argentina y Americana «Dr. Emilio Ravignani», Tercera serie, N²6, pp. 75-116.

Ravines, E.(1952). La gran estafa. Libros y Revistas S.A. México. 
Reedy, D.(2000). Magda Portal, la pasionaria peruana: biografía intelectual. Lima: Ediciones Flora Tristán.

Sánchez, L. (1936). Haya de la Torre o el político, crónica de una vida sin tregua, 2da edición, corregida. Ediciones Ercilla Santiago de Chile.

Sánchez, L.(1969). Testimonio personal: memorias de un peruano del siglo XX. Lima: Ediciones Villazán.

Sánchez, L.(1978). Apuntes para una biografía del APRA. Lima: Mosca Azul Editores.

Sánchez, L. (1982).Correspondencia (1924-1976). Lima: Mosca Azul Editores.

Scenna, M.(1983). F.O.R.J.A., una aventura argentina: de Yrigoyen a Perón Scenna, Miguel Ángel Editorial de Belgrano. Buenos Aires. Colección Testimonios contemporáneos.

Sessa, L. (2010). Solo el aprismo salvará a la Argentina. Una reconstrucción de la militancia aprista en la Argentina a fines de la década de 1930. Apuntes. Revista De Ciencias Sociales, (67), 37-65. Disponible en: https://doi.org/https://doi.org/10.21678/apuntes.67.608

Sessa, L.(2013). Aprismo y apristas en la Argentina. "Derivas de una experiencia antiimperialista en la encrucijada ideológica y politica de los años treinta» (Tesis Doctorado), Universidad Nacional de La Plata. Disponible en: http://www.memoria.fahce.unlp.edu.ar/tesis/ te.824/te.824.pdf

Stein, S. (1982). El APRA, los años de formación. Histórica, VI. (1), Julio 1982.

Townsend, A. (1989). 50 años de aprismo. Memorias, ensayos y discursos de un militante. Lima: p. 175.

Villanueva, A. y Thorndike, G. (2004). La gran persecución. Lima: Universidad de San Martín de Porres.

\section{Archivos de revistas}

Murillo, Percy: En la Argentina peronista y postperonista.

Por la libertad y la vida de Haya de la Torre y Luis Heysen, Claridad, abril de 1938.

Mesa revuelta, Claridad, № 321, enero de 1938.

El hombre de indoamérica, Reforma, julio de 1938. 